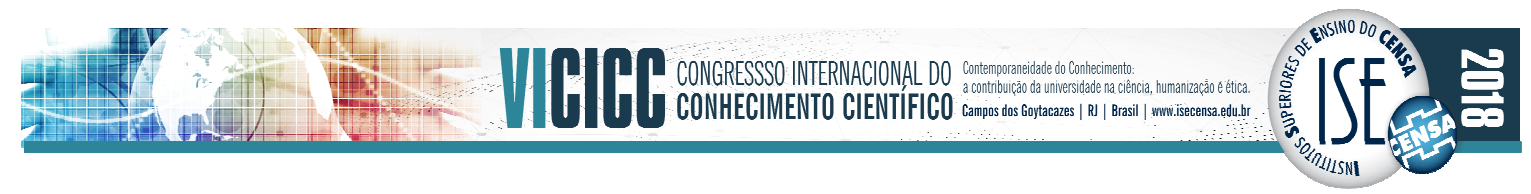

Revista Perspectivas Online: Humanas \& Sociais Aplicadas- Anais do VI CICC

V. 08, № 22, Suplemento, 2018

ISSN: 2236-8876

\title{
UM OLHAR SOBRE A TIMIDEZ NA ADOLESCÊNCIA
}

\section{MILLENA G. M. DE FREITAS, ${ }^{2}$ ANNA CAROLINA WEIDMANN, ${ }^{2}$ BRENO P. DE MÔNICO, ${ }^{2}$ ÉRICA H. RIBEIRO-ANDRADE, ${ }^{1}$}

(1) Docente dos Cursos de Psicologia, Educação Física e Pedagogia dos Institutos Superiores de Ensino do CENSA - ISECENSA, Rua Salvador Correa, 139, Centro, Campos dos Goytacazes, RJ, Brasil; (2) Acadêmicos do Curso de Psicologia do ISECENSA.

O presente estudo foi realizado, por alunos do terceiro período do curso de graduação em Psicologia dos Institutos Superiores de Ensino do CENSA, para cumprimento das exigências da disciplina Psicologia da Adolescência. Autores argumentam que "adolescência" é um termo referente a uma fase essencial para a formação da identidade do sujeito, que vivencia diversos sofrimentos psicológicos, como a timidez. O estudo objetivou avaliar em uma amostra de adolescentes de instituições públicas e privadas o aspecto "timidez" na experiência dos mesmos. Este estudo foi realizado sob metodologia de pesquisa-ação, tendo uma parte de revisão de literatura e outra baseada na aplicação de 20 questionários estruturados. A aplicação foi feita em adolescentes com idade entre 12 a 17 anos, estudantes de escolas públicas e privadas. Para etapa da aplicação dos questionários nos adolescentes, foi necessário o preenchimento, por parte dos responsáveis dos participantes, dos Termos de Consentimento Livre e Esclarecido. Seguida a esta etapa, foi realizada a análise dos dados quanto à timidez na adolescência. $\mathrm{Na}$ aplicação dos questionários não foram encontradas dificuldades relevantes. Dos 20 participantes da amostra, foram distribuídos $50 \%$ de instituições públicas, e $50 \%$ de instituições privadas. No decorrer da análise dos dados foi possível notar que a timidez é uma característica muito presente na vida do adolescente, uma vez que atrapalha no convívio social. A partir da teoria levantada, autores afirmam que a timidez afeta mais de $50 \%$ da população. Aproximadamente $45 \%$ dos participantes da pesquisa de campo defendem ser afetados pela timidez. O resultado da pesquisa revela que meninas estudantes de instituições privadas são mais tímidas, se comparadas aos entrevistados do gênero masculino e de instituições públicas. Foi percebida uma quantidade reduzida de materiais teóricos, como artigos e livros, que abordassem a timidez no período da adolescência, de forma específica, o que resultou em dificuldades para a realização do estudo, e devido a esse fato, entende-se ser necessário um maior número de pesquisas que discutam sobre o tema e o desenvolvimento de pesquisas que contem com a ampliação da amostra participante, para que sejam alcançados resultados mais conclusivos sobre o tema.

Palavras-chave: adolescência, timidez, psicologia da adolescência. 